\title{
Amalgamation of technology, advance trachea-carinal plasty technique, extensive non-intubated thoracic surgery experience and knowledge: the jigsaw pieces all coming together?
}

\author{
Calvin S. H. Ng, Joyce W. Y. Chan, Rainbow W. H. Lau \\ Division of Cardiothoracic Surgery, Department of Surgery, Prince of Wales Hospital, The Chinese University of Hong Kong, Hong Kong SAR, \\ China \\ Correspondence to: Calvin S. H. Ng, MD, FRCS. Professor, Division of Cardiothoracic Surgery, Department of Surgery, The Chinese University of \\ Hong Kong, Prince of Wales Hospital, Hong Kong SAR, China. Email: calvinng@surgery.cuhk.edu.hk. \\ Comment on: Li S, Ai Q, Liang H, et al. Non-intubated Robotic-Assisted Thoracic Surgery for Tracheal/Airway Resection and Reconstruction: \\ Technique Description and Preliminary Results. Ann Surg 2021. [Epub ahead of print]. doi: 10.1097/SLA.0000000000004887.
}

Submitted Sep 15, 2021. Accepted for publication Sep 27, 2021.

doi: $10.21037 /$ atm-21-4859

View this article at: https://dx.doi.org/10.21037/atm-21-4859

The development and increasing popularity of roboticassisted thoracic surgery (RATS) in the past decade has been rapid and undeniable. Despite the large numbers of publications, there remains to be seen good evidence from large randomized controlled trial of RATS versus video-assisted thoracic surgery (VATS) anatomical lung resection for lung cancer. It is indeed only recently, after almost 30 years since the first VATS major lung resection was performed, that the VIOLET study showed VATS for resectable lung cancer was associated with less pain, fewer in-hospital complications and shorter hospital stay, achieved without any compromise to early oncologic outcomes, when compared with open procedure. Nevertheless, a number of well conducted meta-analysis of the available literature comparing RATS and VATS for lung cancer have found no conclusive evidence that one is superior $(1,2)$. Of note, a number of experienced users and early pioneers of the robotic platform have commented on the advance maneuverability with seven degrees of freedom being ideal for complex bronchoplastic procedures, with some even going as far as choosing to dock the robot for the suture anastomosis (3). In this recent article in Annals of Surgery from Prof. He's team (4), they performed 5 cases of RATS for tracheal/carinal resection and reconstruction with the now widely accepted technique of non-intubated spontaneous ventilation anaesthesia. The preliminary and early results for these select patients are excellent, with no complications up to 1-month follow-up. They also employed the technique of continuous suture anastomosis, which the group has championed, to perform the complex airway reconnections. Their approach pushes further the limits and boundaries of minimally invasive thoracic surgery capabilities.

Non-intubated thoracic surgery (NITS) was advocated by Pompeo (5) initially for limited lung resections in treatment of pneumothorax and solitary lung nodules, and was subsequently developed by a number of groups including He's team for more complex major lung resections $(6,7)$. Studies have shown the non-intubated approach is associated with an attenuated pro-inflammatory mediator response, earlier resumption of oral feeding following surgery, and shorter hospital stay following certain procedures, as well as avoids potential complications from endotracheal intubation (7). Nevertheless, careful patient selection is required, with patients in general with American Society of Anesthesiology score of $>3$, severe obesity, and an arterial $\mathrm{CO}_{2}$ tension of $>55 \mathrm{mmHg}$ among others considered contraindicated for non-intubated surgery (7). The epitome of NITS was reported in 2018 for performing VATS tracheal-carina resection reconstructions (8). Sixteen patients who underwent NITS VATS tracheal carina resections were compared with historical conventional general anaesthetic controls, showing a trend towards shorter postoperative hospital stay in NITS, while safety and oncological results were comparable in select patients (8).

The development of robot-assisted thoracic surgery has been rapid, but none more so than in the past few years. 
Recent reports of robot-assisted highly complex lung surgery including sleeve and double sleeve resections have grown (9). Improvements in the latest generation of robotic platform, and the build-up of experience and skill to reconstruct airways by minimally invasive approach, particularly the change to use of continuous suturing technique (8), has provided the foundations for and the confidence to perform NITS RATS tracheal/carinal resection reconstruction. Taking a quote from Confucius, "success depends upon previous preparation, and without such preparation there is sure to be failure". The non-intubated RATS for tracheal/airway resection and reconstruction procedure is not for beginners in robotic surgery, nor is it for those with limited experience in complex airway reconstruction. It also goes without saying that complex airway reconstruction would be inappropriate case selection for someone starting on NITS. However, what we observe here is the perfect amalgamation of precision robotic technology, advance trachea-carinal plasty technique, extensive NITS experience and knowledge (TTEK) in case selection all falling into place. What is missing in the jigsaw? Perhaps a world of autonomous robotic lung surgery.

\section{Acknowledgments}

Funding: None.

\section{Footnote}

Provenance and Peer Review: This article was commissioned by the editorial office, Annals of Translational Medicine. The article did not undergo external peer review.

Conflicts of Interest: All authors have completed the ICMJE uniform disclosure form (available at https://dx.doi. org/10.21037/atm-21-4859). CSHN is a consultant for Johnson and Johnson, Medtronic, USA and Siemens Healthineers. RWHL is a consultant for Medtronic, USA; and Siemens Healthineers. The other author has no conflicts of interest to declare.

Ethical Statement: The authors are accountable for all aspects of the work in ensuring that questions related to the accuracy or integrity of any part of the work are appropriately investigated and resolved.

Open Access Statement: This is an Open Access article distributed in accordance with the Creative Commons Attribution-NonCommercial-NoDerivs 4.0 International
License (CC BY-NC-ND 4.0), which permits the noncommercial replication and distribution of the article with the strict proviso that no changes or edits are made and the original work is properly cited (including links to both the formal publication through the relevant DOI and the license). See: https://creativecommons.org/licenses/by-nc-nd/4.0/.

\section{References}

1. Ng CSH, MacDonald JK, Gilbert S, et al. Optimal Approach to Lobectomy for Non-Small Cell Lung Cancer: Systemic Review and Meta-Analysis. Innovations (Phila) 2019;14:90-116.

2. Ma J, Li X, Zhao S, et al. Robot-assisted thoracic surgery versus video-assisted thoracic surgery for lung lobectomy or segmentectomy in patients with non-small cell lung cancer: a meta-analysis. BMC Cancer 2021;21:498.

3. Schmid T, Augustin F, Kainz G, et al. Hybrid video-assisted thoracic surgery-robotic minimally invasive right upper lobe sleeve lobectomy. Ann Thorac Surg 2011;91:1961-5.

4. Li S, Ai Q, Liang H, et al. Non-intubated Robotic-Assisted Thoracic Surgery for Tracheal/Airway Resection and Reconstruction: Technique Description and Preliminary Results. Ann Surg 2021. [Epub ahead of print]. doi: 10.1097/SLA.0000000000004887.

5. Pompeo E. Pathophysiology of surgical pneumothorax in the awake patient. In: Pompeo E. editor. Awake thoracic surgery. Sharja: Bentham Science Publishers, 2012:9-18.

6. Zhao ZR, Lau RW, Ng CS. Non-intubated video-assisted thoracic surgery: the final frontier? Eur J Cardiothorac Surg 2016;50:925-6.

7. Zhao ZR, Ng CSH. Awake, non-intubated transpleural surgery. In: LoCicero J III, Feins RH, Colson YL, et al. editors. Shield's General Thoracic Surgery 8th Edition. Alphen aan den Rijn: Wolters Kluwer, 2018:497-501.

8. Jiang L, Liu J, Gonzalez-Rivas D, et al. Thoracoscopic surgery for tracheal and carinal resection and reconstruction under spontaneous ventilation. J Thorac Cardiovasc Surg 2018;155:2746-54.

9. Shanahan B, O'Sullivan KE, Redmond KC. Robotic sleeve lobectomy-recent advances. J Thorac Dis 2019;11:1074-5.

Cite this article as: $\mathrm{Ng}$ CSH, Chan JWY, Lau RWH. Amalgamation of technology, advance trachea-carinal plasty technique, extensive non-intubated thoracic surgery experience and knowledge: the jigsaw pieces all coming together? Ann Transl Med 2021;9(21):1633. doi: 10.21037/atm-21-4859 